\title{
Anomalous Temperature Dependence of Crystalline-to-Amorphous Transformation Induced by High-Pressure Torsion in $\mathrm{Zr}_{50}(\mathrm{Cu}, \mathrm{Al})_{50}$
}

\author{
Fanqiang Meng ${ }^{1, *}$, Koichi Tsuchiya ${ }^{1,2}$, Qingsong Mei ${ }^{1}$, Baozhen Jiang $^{1,2}$ and Yoshihiko Yokoyama ${ }^{3}$ \\ ${ }^{1}$ Structural Materials Unit, National Institute for Materials Science, Tsukuba 305-0047, Japan \\ ${ }^{2}$ Graduate School of Pure and Applied Sciences, University of Tsukuba, Tsukuba 305-8577, Japan \\ ${ }^{3}$ Institute for Materials Research, Tohoku University, Sendai 980-8577, Japan
}

Martensite phases of $\mathrm{Zr}_{50} \mathrm{Cu}_{50}$ and $\mathrm{Zr}_{50} \mathrm{Cu}_{44} \mathrm{Al}_{6}$ were deformed by high-pressure torsion (HPT) at different temperatures ranging from 253 to $473 \mathrm{~K}$. Microstructural observations revealed that the crystalline-to-amorphous transformation induced by HPT showed remarkable temperature dependence: an increase in deformation temperature up to $473 \mathrm{~K}$ significantly increased the fraction of the amorphous structure. This result suggests that the lattice instability near martensitic transformation temperature promotes crystalline-to-amorphous transformation, which is coherent to the generalized Lindemann criterion of defect-induced amorphization. [doi:10.2320/matertrans.M2013049]

(Received February 5, 2013; Accepted April 19, 2013; Published June 7, 2013)

Keywords: amorphization, high pressure torsion, lattice instability, zirconium-copper-aluminum

\section{Introduction}

Amorphous alloys have been studied extensively as potential structural materials. ${ }^{1)}$ In contrast to crystalline materials, amorphous alloys are characterized by the absence of long-range order in atomic arrangements, resulting in a unique combination of properties, including ultra-high strength, high elastic limit and excellent corrosion resistance. ${ }^{2)}$ Alloys with amorphous structure can be produced by different methods, such as rapid quenching of the melts, ${ }^{3)}$ or the crystalline-to-amorphous transformation (CTAT) by severe plastic deformation (SPD) ${ }^{4}{ }^{4}$ Several bulk SPD techniques, such as shot peening, ${ }^{5}$ ) high-pressure torsion $(\mathrm{HPT})^{6-8)}$ and cold drawing ${ }^{9)}$ have been utilized to produce amorphous structures in TiNi and $\mathrm{ZrCu}$ via CTAT. HPT is believed to be one of the most effective methods to produce and deform amorphous materials, ${ }^{10,11)}$ by which ultrahigh plastic deformation can be applied.

Previous studies demonstrated that the amorphization via CTAT induced by HPT is not only dependent on the accumulative strain applied on the sample, ${ }^{7,12)}$ but also on the deformation temperature $\left.\left(T_{\text {def }}\right) .{ }^{13,14}\right)$ The tendency to form amorphous structure by HPT in TiNi is reported to be the most pronounced when the $T_{\text {def }}$ is far below the martensitic transformation starting temperature $\left(M_{\mathrm{s}}\right)$, intermediate when the $T_{\text {def }}$ lies somewhat above $M_{\mathrm{s}}$, and the weakest when $T_{\text {def }}$ is far above $M_{\mathrm{s}}{ }^{13)}$ However, it is still unknown if this tendency may be applied to other materials with higher $M_{\mathrm{s}}$, such as $\mathrm{Zr}_{50} \mathrm{Cu}_{50}$, which undergoes martensitic transformation from B2 to $\mathrm{Cm}$ or B19' phases at $443 \mathrm{~K} .{ }^{15)}$ Previous study revealed that $M_{\mathrm{s}}$ in $\mathrm{ZrCu}$ decreases by an $\mathrm{Al}$ addition ${ }^{16)}$ and $\mathrm{Zr}(\mathrm{Cu}, \mathrm{Al})$ are also favorable for producing amorphous structure by either rapid quenching or CTAT, ${ }^{7,17)}$ which is suitable for the investigation of temperature dependence of amorphization. In the present study, the effect of $T_{\text {def }}$ on the amorphization process under HPT deformation was investigated in $\mathrm{Zr}_{50} \mathrm{Cu}_{50}$ and $\mathrm{Zr}_{50} \mathrm{Cu}_{44} \mathrm{Al}_{6}$. The microstructural evolution revealed that the maximum fraction of amorphous

*Corresponding author, E-mail: meng.fanqiang@nims.go.jp phase was obtained at the temperature near $A_{\mathrm{s}}$ (starting temperature of reverse martensitic transformation), but not lower than $M_{\mathrm{s}}$.

\section{Experimental Procedure}

Cylindrical ingots with a diameter of $10 \mathrm{~mm} \mathrm{Zr}_{50} \mathrm{Cu}_{50}$ and $\mathrm{Zr}_{50} \mathrm{Cu}_{44} \mathrm{Al}_{6}$ were prepared by the tilt-casting method, and crystallization heat treatment of $\mathrm{Zr}_{50} \mathrm{Cu}_{44} \mathrm{Al}_{6}$ was performed at $1073 \mathrm{~K}$ for $72 \mathrm{~h}$, followed by water quenching. Martensitic transformation temperatures were calorimetrically measured to be $M_{\mathrm{s}}=446 \mathrm{~K}$ and $A_{\mathrm{s}}=537 \mathrm{~K}$ in as-cast $\mathrm{Zr}_{50} \mathrm{Cu}_{50}$, $M_{\mathrm{s}}=311 \mathrm{~K}$ and $A_{\mathrm{s}}=468 \mathrm{~K}$ in as-crystallized $\mathrm{Zr}_{50} \mathrm{Cu}_{44} \mathrm{Al}_{6}$, respectively. Disks of $0.85 \mathrm{~mm}$ thick sliced from the rods were subjected to HPT deformation using constrainedgeometry anvils ${ }^{18)}$ under compressive pressure of $5 \mathrm{GPa}$ at a rotation speed of $1 \mathrm{rpm}$ to 10 and 20 revolutions. Before HPT deformation, $\mathrm{Zr}_{50} \mathrm{Cu}_{44} \mathrm{Al}_{6}$ samples were dipped into liquid nitrogen, aiming to exclude the residual $\mathrm{B} 2 \mathrm{ZrCu}$ phase completely via martensitic transformation. ${ }^{15,16)}$ In order to investigate the effect of $T_{\text {def }}$ on the amorphization behaviors, HPT was performed at different temperatures, for example, HPT deformation with 20 revolutions in the $\mathrm{Zr}_{50} \mathrm{Cu}_{44} \mathrm{Al}_{6}$ samples was carried out at five temperatures: $253 \pm 5 \mathrm{~K}$, $306 \pm 7 \mathrm{~K}, 325 \pm 4 \mathrm{~K}, 373 \pm 1 \mathrm{~K}$ and $473 \pm 3 \mathrm{~K}$ (average values of measurements taken every $30 \mathrm{~s}$ ). Deformation at $306 \mathrm{~K}$ was performed in the air without heating or cooling. Liquid nitrogen was used to cool the anvils when deformation was carried out at $T_{\mathrm{def}}<306 \mathrm{~K}$, and a cylindrical furnace fixed on the upper anvil was used to heat the anvils at $T_{\text {def }}>306 \mathrm{~K}$. The actual temperature evolution during HPT processing was recorded by a thermo couple embedded in the upper anvil. ${ }^{18)}$

Planar samples were mechanically ground down to roughly the median plane for X-ray diffraction (XRD) characterization, performed on RIGAKU RINT TTRIII diffractometer with $\mathrm{Cu}-\mathrm{K}_{\alpha}$ radiation $(40 \mathrm{kV}, 150 \mathrm{~mA})$. Microstructural evolution was studied by optical microscopy (OM) and transmission electron microscopy (TEM). For TEM observations, disc samples with $3 \mathrm{~mm} \phi$ were cut from the position 

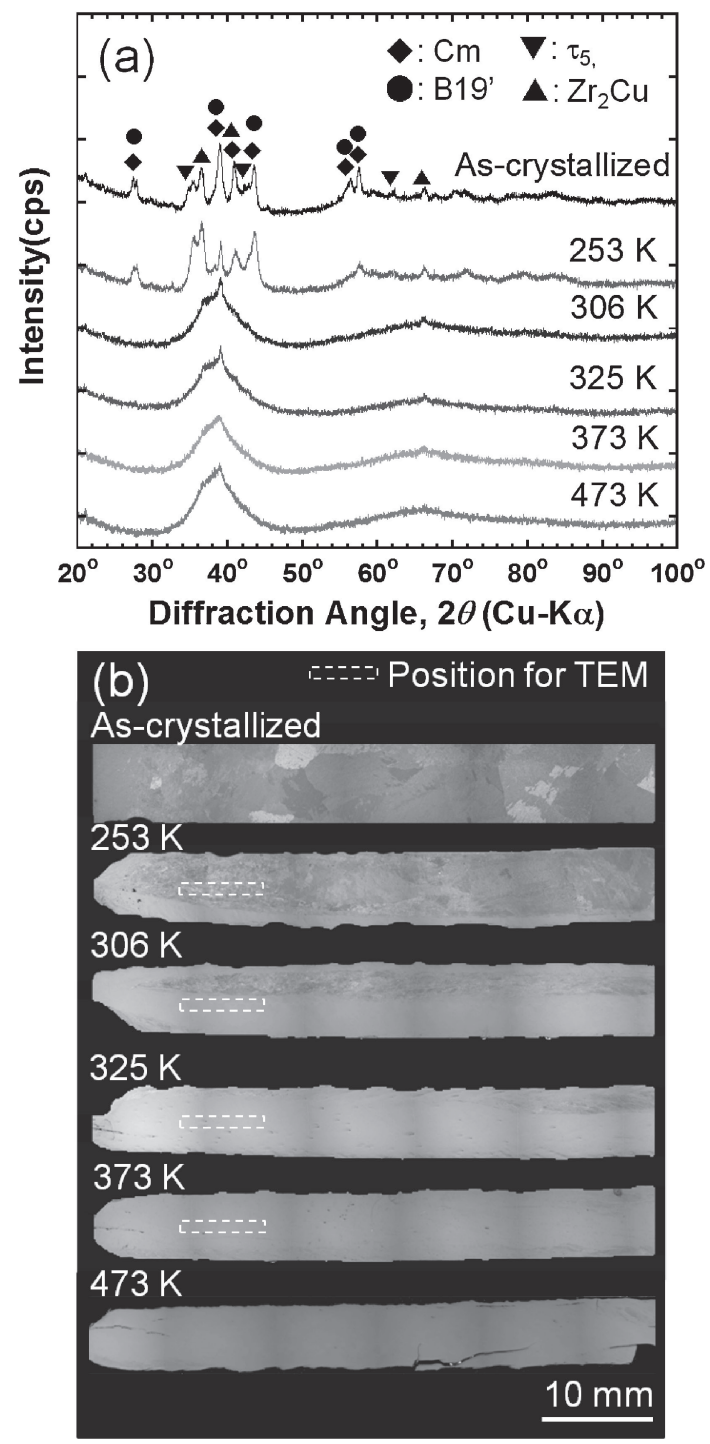

Fig. 1 (a) X-ray diffraction profiles and (b) optical images of cross-sections in the $\mathrm{Zr}_{50} \mathrm{Cu}_{44} \mathrm{Al}_{6}$ samples before and after HPT deformation with 20 revolutions at different temperatures.

about $3.5 \mathrm{~cm}$ away from the center in the median plane of the deformed samples (shown in Fig. 1(b)), and electropolishing was done using Tenupol-3 with an electrolyte consisting of $20 \mathrm{vol} \%$ nitric acid and methanol at temperature of $253 \mathrm{~K}$. TEM observations were performed on JEOL JEM-2100 operated at an accelerating voltage of $200 \mathrm{kV}$.

\section{Results and Discussion}

XRD profiles of the $\mathrm{Zr}_{50} \mathrm{Cu}_{44} \mathrm{Al}_{6}$ samples before and after HPT deformation with 20 revolutions at different temperatures are shown in Fig. 1(a). XRD peaks can be assigned to $\mathrm{Zr}_{2} \mathrm{Cu}, \tau_{5}$ and martensite phases with $\mathrm{Cm}$ and $\mathrm{B} 19$ ' structure in the as-crystallized sample. Peak broadening occurs in the sample deformed at $253 \mathrm{~K}$, indicating the refinement of crystalline size and increasing dislocation density. The appearance of a broad diffraction hump along with some weak diffraction peaks in the XRD profiles of the samples deformed at the temperatures higher than $253 \mathrm{~K}$ reveals the formation of amorphous phase with some residual crystals.
The OM observations on the cross-section of the $\mathrm{Zr}_{50} \mathrm{Cu}_{44} \mathrm{Al}_{6}$ before and after HPT deformation of 20 revolutions at different temperatures are shown in Fig. 1(b). The contrast in the as-crystallized sample is from grains with martensite structure, as confirmed by XRD (Fig. 1(a)) and TEM (not shown) investigations. Such contrast is used to label the microstructural evolution at different conditions. After HPT deformation at $253 \mathrm{~K}$, featureless structure (FLS), characterized by the absence of microstructural contrast, is observed at the bottom surface. The area of FLS becomes larger in the sample deformed at $306 \mathrm{~K}$ compared to that at $253 \mathrm{~K}$. Since the XRD results shown in Fig. 1(a) are measured on the median planar plane of the deformed samples, the presence of broad diffraction hump indicates that the FLS is corresponding to amorphous structure, which has also been confirmed by TEM observations shown in Fig. 2. A continuous increase in the deformation temperature from 306 to $325 \mathrm{~K}$ leads to the significant increase in the area of FLS. When the deformation temperature is higher than $325 \mathrm{~K}$, only slight increase in the amount of FLS can be observed accompanying with a small amount of original martensite structure in the edge and center of the disc.

TEM observations were conducted on the deformed $\mathrm{Zr}_{50} \mathrm{Cu}_{44} \mathrm{Al}_{6}$ with 20 revolutions to clarify the detailed microstructure change at different conditions and the positions for TEM observations have been marked in Fig. 1(b). Bright-field images with the corresponding selected area electron diffraction (SAED) patterns are shown in Fig. 2. It can be seen in Fig. 2(a) that HPT deformation introduces many shear bands after 20 revolutions at $253 \mathrm{~K}$. The SAED spots in Fig. 2(a) from the martensite phases are stretched severely, implying the accumulative straining achieved. Microstructural observation in the sample deformed at $306 \mathrm{~K}$ indicates the formation of amorphous phase, which has been confirmed by the SAED pattern in Fig. 2(b). While there are still some grains with different sizes in this sample, the coarse grains in the bottom right of Fig. 2(b) indicates the structural inhomogeneity. TEM observation in the sample deformed at $306 \mathrm{~K}$ also reveals that the FLS is mainly composed of amorphous structure, which is consistent with the XRD results. In the samples deformed at 325 and $373 \mathrm{~K}$, the SAED patterns shown in Fig. 2(c) and 2(d) also exhibit diffuse rings, indicating amorphous phase. In addition, the grains with average grain sizes of about 10$50 \mathrm{~nm}$ are distributed in an amorphous matrix in Fig. 2(c) and 2(d). Comparing to the sample deformed at $325 \mathrm{~K}$ in Fig. 2(c), finer distribution of nanograins is observed in the Fig. 2(d). The nanograins in Fig. 2(d) are mostly isolated from each other and with smaller size, which are different from the nanograins distributed in Fig. 2(b) and 2(d). Therefore most of these nanocrystals in Fig. 2(d) may be produced by the crystallization of the amorphous phase. Similar OM and TEM results and tendency were obtained in the as-cast $\mathrm{Zr}_{50} \mathrm{Cu}_{50}$ with only martensite phases ${ }^{16)}$ after HPT deformation at different temperatures.

All these results strongly suggest that an increase in the deformation temperature facilitates the formation of amorphous structure. In order to quantify the evolution of amorphous structure with the deformation temperature, we simply assume the FLS is only composed of amorphous 

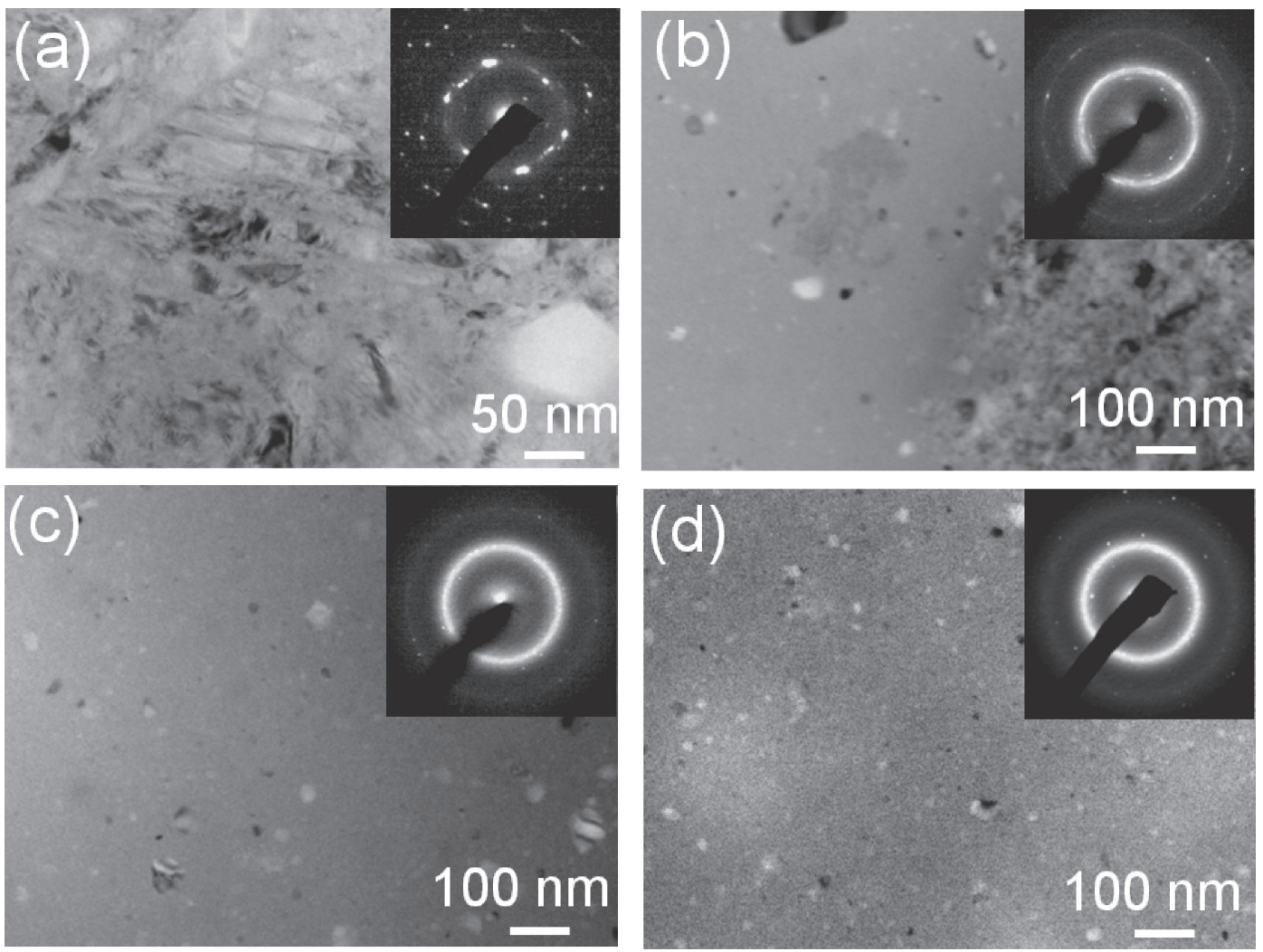

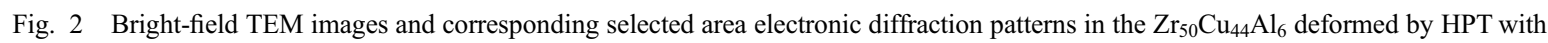
20 revolutions at different temperatures, (a) $253 \mathrm{~K}$, (b) $306 \mathrm{~K}$, (c) $325 \mathrm{~K}$ and (d) $373 \mathrm{~K}$.

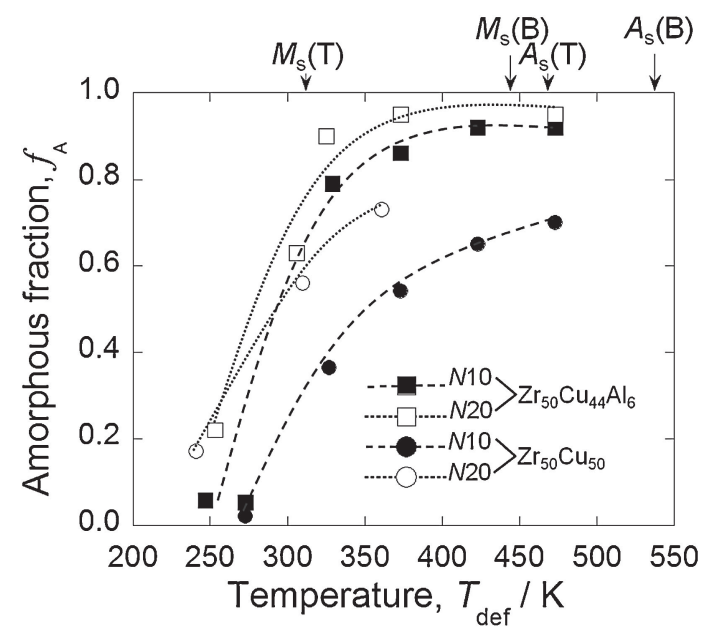

Fig. 3 Amorphous fraction $\left(f_{\mathrm{A}}\right)$ as a function of $T_{\text {def }}$ in $\mathrm{Zr}_{50} \mathrm{Cu}_{50}(\mathrm{~B})$ and $\mathrm{Zr}_{50} \mathrm{Cu}_{44} \mathrm{Al}_{6}$ (T) deformed with 10 (N10) and 20 revolutions (N20). The $M_{\mathrm{s}}$ and $A_{\mathrm{s}}$ are marked.

structure, ignoring the nanocrystals. The area fraction of amorphous structure $\left(f_{\mathrm{A}}\right)$ is defined as the sum area of FLS over whole area of the cross section in the deformed sample. The calculated $f_{\mathrm{A}}$ in the $\mathrm{Zr}_{50} \mathrm{Cu}_{50}$ and $\mathrm{Zr}_{50} \mathrm{Cu}_{44} \mathrm{Al}_{6}$ after 10 (N10) and $20(N 20)$ revolutions are plotted in Fig. 3 as a function of the $T_{\text {def }}$ and the $M_{\mathrm{s}}$ and $A_{\mathrm{s}}$ in both alloys have been signed. In the $\mathrm{Zr}_{50} \mathrm{Cu}_{44} \mathrm{Al}_{6}$ after either 10 or 20 revolutions, $f_{\mathrm{A}}$ increases significantly with the increasing $T_{\text {def }}$ and approaches saturation as $T_{\mathrm{def}}>325 \mathrm{~K}$. The variation of $f_{\mathrm{A}}$ with the $T_{\text {def }}$ in the deformed $\mathrm{Zr}_{50} \mathrm{Cu}_{50}$ after 10 and 20 revolutions exhibits analogous temperature dependence to $\mathrm{Zr}_{50} \mathrm{Cu}_{44} \mathrm{Al}_{6}$, while the saturation temperature has not been reached. The more revolutions also result in a larger $f_{\mathrm{A}}$ at the same $T_{\text {def }}$ in both alloys. Figure 3 demonstrates that the $f_{\mathrm{A}}$ in both alloys increases with the increasing $T_{\text {def }}$, but it saturates at lower temperature in $\mathrm{Zr}_{50} \mathrm{Cu}_{44} \mathrm{Al}_{6}$ than in $\mathrm{Zr}_{50} \mathrm{Cu}_{50}$. At a constant temperature and revolution, higher $f_{\mathrm{A}}$ was obtained in $\mathrm{Zr}_{50} \mathrm{Cu}_{44} \mathrm{Al}_{6}$ than in $\mathrm{Zr}_{50} \mathrm{Cu}_{50}$. These results suggest that increasing $T_{\text {def }}$ toward $A_{\mathrm{s}}$ (well above $M_{\mathrm{s}}$ ) in both compounds can enhance the formation of amorphous phase, which is in contradiction to the previous observations that the tendency to form amorphous structure in NiTi deformed by HPT is most pronounced when $T_{\text {def }}$ is below $M_{\mathrm{s}}{ }^{13}$ ) The possible explanation for this difference may be related to the different rotation speed, which is $1 \mathrm{rpm}$ in present study and $11.6 \mathrm{rpm}$ in the reference. ${ }^{13)}$

In the present study, the accumulative shear strain imposed by HPT is identical for the all conditions, but the fraction of amorphous structure is significantly different, indicating the amorphization in both alloys is strongly dependent on the $T_{\text {def. }}$ Possible understanding of the present results can be made by considering the generalized Lindemann melting criterion $^{4)}$ and lattice instability near reverse martensitic transition temperature. The generalized Lindeman criterion is the extension of thermally induced melting criterion to defect induced melting (or amorphization), and can be written as:

$$
\left\langle\mu_{\text {cri }}^{2}\right\rangle=\left\langle\mu_{\text {vib }}^{2}\right\rangle+\left\langle\mu_{\text {sta }}^{2}\right\rangle
$$

where $\left\langle\mu_{\mathrm{x}}^{2}\right\rangle$ is the mean square displacement of atoms from the equilibrium positions in a crystalline lattice. The left hand 
side of the eq. (1), $\left\langle\mu_{\text {cri }}^{2}\right\rangle$, is the critical value of the mean square displacement for melting or amorphization. In the right hand side, $\left\langle\mu_{\mathrm{vib}}^{2}\right\rangle$ is the mean square displacement due to thermal vibration (which linearly increases with temperature), and $\left\langle\mu_{\mathrm{sta}}^{2}\right\rangle$ is the static displacement caused by lattice defects (dislocations, vacancies, etc.). Thermal melting of a perfect crystal occurs when the thermal vibration term, $\left\langle\mu_{\mathrm{vib}}^{2}\right\rangle$, reaches the critical mean square displacement for melting, i.e., $\left\langle\mu_{\mathrm{cri}}^{2}\right\rangle=\left\langle\mu_{\mathrm{vib}}^{2}\right\rangle$. Introduction of a high density of lattice defect leads to an enhanced contribution of $\left\langle\mu_{\text {sta }}^{2}\right\rangle$; then the criterion may be satisfied even at low temperatures, where the atomic mobility is low enough to freeze the amorphous liquid structure. In martensitic alloys, e.g., $\mathrm{Fe}-\mathrm{Pd}^{19)}$ or intermetallic compounds (e.g., $\mathrm{TiNi}^{20)}$ ) it is widely known that the shear modulus decreases markedly in the temperature range at around martensitic transformation temperature due to the softening of the $\mathrm{TA}_{1}$ branch of phonon dispersion curve at a particular wave vector. ${ }^{19)}$ Elastic modulus of $\mathrm{Zr}_{50} \mathrm{Cu}_{50}$ also exhibits a pronounced minimum at around the martensitic transformation temperature. ${ }^{21)}$ In addition to the enhanced $\left\langle\mu_{\text {sta }}^{2}\right\rangle$ due to the high defect density, such lattice instability can further enhance the contribution of $\left\langle\mu_{\mathrm{vib}}^{2}\right\rangle$ near the martensitic transformation temperature. This facilitates the enhanced amorphization as $T_{\text {def }}$ approaches the martensitic transformation temperature. The difference of martensite transformation temperatures in $\mathrm{Zr}_{50} \mathrm{Cu}_{50}$ and $\mathrm{Zr}_{50} \mathrm{Cu}_{44} \mathrm{Al}_{6}$ then may explain the difference in the temperature dependence of amorphous formation with the same level of deformation by HPT.

\section{Conclusions}

In summary, we have found an anomalous temperature effect on the crystal-to-amorphous transformation in $\mathrm{Zr}_{50}(\mathrm{Cu}, \mathrm{Al})_{50}$ deformed by HPT. Increasing the HPT processing temperature up to near $A_{\mathrm{s}}$ remarkably promoted the formation of the amorphous phase. These results can be interpreted by the generalized Lindemann criteria and lattice instability near the martensitic transformation temperature. The present results emphasize the importance of a careful consideration of temperature effects on microstructural evolution during HPT, and provide important clues for understanding the amorphization behavior induced by plastic deformation.

\section{Acknowledgements}

This work was supported in part by Grant-in-Aid for Scientific Research on Innovative Area, "Bulk Nanostructured Metals", through MEXT, Japan (contract No. 22102004). The work was conducted under the interuniversity cooperative research program of the Institute for Materials Research, Tohoku University.

\section{REFERENCES}

1) C. A. Schuh, T. C. Hufnagel and U. Ramamurty: Acta Mater. 55 (2007) 4067-4109.

2) Y. Q. Cheng and E. Ma: Prog. Mater. Sci. 56 (2011) 379-473.

3) P. Duwez, R. H. Willens and W. Klement: J. Appl. Phys. 31 (1960) 1136-1137.

4) P. R. Okamoto, N. Q. Lam and L. E. Rehn: Solid State Phys. 52 (1998) 1-135.

5) D. M. Grant, S. M. Green and J. V. Wood: Acta Metall. Mater. 43 (1995) 1045-1051.

6) T. Waitz: Acta Mater. 53 (2005) 2273-2283.

7) K. Tsuchiya and O. Ciuca: Mater. Sci. Forum 667-669 (2011) 17-24.

8) J. Y. Huang, Y. T. Zhu, X. Z. Liao and R. Z. Valiev: Philos. Mag. Lett. 84 (2004) 183-190.

9) K. Tsuchiya, Y. Hada, T. Koyano, K. Nakajima, M. Ohnuma, T. Koike, Y. Todaka and M. Umemoto: Scr. Mater. 60 (2009) 749-752.

10) A. P. Zhilyaev and T. G. Langdon: Prog. Mater. Sci. 53 (2008) 893-979.

11) F. Q. Meng, K. Tsuchiya, S. Ii and Y. Yokoyama: App. Phys. Lett. 101 (2012) 121914.

12) F. Q. Meng, K. Tsuchiya and Y. Yokoyama: Intermetallics 37 (2013) 52-58.

13) S. D. Prokoshkin, I. Y. Khmelevskaya, S. V. Dobatkin, I. B. Trubitsyna, E. V. Tatyanin, V. V. Stolyarov and E. A. Prokofiev: Acta Mater. 53 (2005) 2703-2714

14) J. C. Ewert, I. Bohm, R. Peter and F. Haider: Acta Mater. 45 (1997) 2197-2206

15) Y. N. Koval, G. S. Firstov and A. V. Kotko: Scr. Metall. Mater. 27 (1992) 1611-1616.

16) F. Q. Meng, K. Tsuchiya, F. X. Yin, S. Ii and Y. Yokoyama: J. Alloy. Compd. 522 (2012) 136-140.

17) L. Q. Xing, P. Ochin and J. Bigot: J. Non-Cryst. Solids 205-207 (1996) 637-640.

18) Y. F. Sun, T. Nakamura, Y. Todaka, M. Umemoto and N. Tsuji: Intermetallics 17 (2009) 256-261.

19) R. Oshima, S. Muto and F. E. Fujita: Mater. Trans. JIM 33 (1992) 197202.

20) T. M. Brill, S. Mittelbach, W. Assmus, M. Mullner and B. Luthi: J. Phys. Condens. Matter 3 (1991) 9621-9627.

21) G. S. Firstov, J. Van Humbeeck and Y. N. Koval: J. De Phys. IV France 11 (2001) Pr8-481-Pr8-486. 